\title{
An Improved DC Motor Position Control Using Differential Evolution Based Structure Specified Hœ Robust Controller
}

\author{
Petrus Sutyasadi \\ Sanata Dharma University, Paingan, Maguwoharjo, Yogyakarta, 55282, Indonesia
}

\begin{tabular}{|c|c|}
\hline ARTICLE INFO & ABSTRACT \\
\hline Article history: & Traditional synthesis of an $\mathrm{H} \infty$ controller usually results in a very high order \\
\hline $\begin{array}{l}\text { Received July 15, } 2021 \\
\text { Revised September 06, } 2021 \\
\text { Accepted October 08, } 2021\end{array}$ & $\begin{array}{l}\text { of controller that is not practical for a low-cost embedded system such as a } \\
\text { microcontroller. This paper presents a synthesis method of a low-order } \mathrm{H} \infty \\
\text { robust controller to control the position of a DC motor. The synthesis } \\
\text { employed Differential Evolution optimization to find a controller that }\end{array}$ \\
\hline Keywords: & perturbation. A second-order PID structure was chosen for the synthesized \\
\hline $\begin{array}{l}\text { DC Motor; } \\
\text { Robust Control; } \\
\text { Ho Control; } \\
\text { Differential Evolution; } \\
\text { PID }\end{array}$ & $\begin{array}{l}\text { controller because this structure is simple and very famous. The proposed } \\
\text { controller performance under uncertainties was compared to some other } \\
\text { controllers. The first was compared with a conventional PID controller that } \\
\text { had been finely tuned using the trial and error method in the nominal transfer } \\
\text { function of the plant. Secondly, the proposed controller was compared with a } \\
\text { full-order Ho robust controller generated from a traditional synthesis method. } \\
\text { Thirdly, the proposed controller was compared with another structure } \\
\text { specified Ho robust controller generated differently from the proposed } \\
\text { method. All of the controllers result in a stable response. However, the } \\
\text { proposed controller gives a better response in terms of overshoot and response } \\
\text { time. }\end{array}$ \\
\hline
\end{tabular}

This work is licensed under a Creative Commons Attribution-Share Alike 4.0

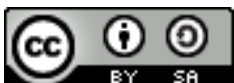

\author{
Petrus Sutyasadi, \\ Sanata Dharma University, Paingan, Maguwoharjo, Yogyakarta 55282, Indonesia \\ Email: peter@usd.ac.id
}

\section{INTRODUCTION}

DC motors are commonly used in industries due to their quick response and high starting torque. With the increased demand for industrial growth, high-precision motion control has emerged as a key development path for modern DC motor control [1]. Some researchers implemented a PID controller to control both the position and speed of the DC motor [2][3][4][5]. In some applications, when the DC motor is used to move some loads such as vehicles or manipulators, the controlling effort begins more interesting. The system will deal more with uncertainties that affect its stability and performance. To overcome the uncertainties, some researchers tried to synthesis a smart PID such as an adaptive PID [6] or hybrid PID such as Neural Network with PID [7]. Nonetheless, to get better control of the system, the controller synthesis needs the model of the system. The modeling process is a common method during research in the robotic and mechatronic fields [8]. A good model helps in many aspects of the system design, such as kinematic and dynamic performance [9], good control system [10], good trajectory tracking [11], vibration reduction [12], and energy efficiency [13]. Simplification is always present in a mathematical modeling process of a physical system. This causes modeling errors that lead to uncertainties for the mathematical model. Too many modeling uncertainties reduce control performance and lead to instability [14]. To reduce the effect of unmodeled disturbances, robust control as the main choice has been investigated by some researchers [15][16][17]. A robust controller is a controller that guarantees the robust stability and robust performance of a system against disturbance or uncertainties. One of the most popular robust control tools is $\mathrm{H} \infty$ control. $\mathrm{H} \infty$ robust controller guarantees the robust stability and robust performance of the system under certain or prescribed worst-case uncertainties [18]. 
Some researchers have conducted research and provided several techniques for Hळ controller synthesis such as a solution in state space [19] and loop shaping [20][21]. Robust Hœ controller was derived by synthesizing the performance index to meet the robust stability and robust performance [22]. Optimizing the performance index that works for both MIMO or SISO systems is shown in [23]. Hळ with observer predictive law was used to stabilize multivariable systems with delay [24]. Another approach was for chaotic system stabilization [25]. Hळ loop shaping for the multivariable system is shown in [26], and a similar method with constrained input is introduced in [27]. In [28], Ho robust controller synthesis to control reluctance motor under uncertainties is shown. While in [29], Ho loop shaping for a 2 degree of freedom is shown. Similarly, the author in [30] showed that an Hळ loop shaping controller was synthesized for industrial motion control. The author in [31] showed an Ho loop shaping controller synthesis with weighting function optimization. A data-driven $\mathrm{H}_{2} \mathrm{H} \infty$ loop shaping is shown in [32]. In [33], the author tried to implement $\mathrm{H} 2 / \mathrm{H} \infty$ robust control to control the DC motor. But, in the controller synthesis, the sensitivity and complementary sensitivity weight were defined by the trial and error process.

The problem for a small embedded system with a low clock rate, such as Arduino or some other small 8bit microcontrollers, is the order of the controller to be programmed on it. Traditional synthesis of H $\infty$ controller always results in a very high order of the controller. Combined with the order of the plant, the overall control will have a very high order of the system. To reduce the order of the controller, a structure-specified $\mathrm{H} \infty$ controller is used. Structure specified $\mathrm{H} \infty$ controller based on Particle Swarm Optimization is used in [34] and [35]. Another optimization method was also introduced in [36] using Genetic Algorithm and [37] using Differential Evolution Optimization to get structure specified $\mathrm{H} \infty$ controller. In [38], the author synthesized a genetic algorithm-based fixed structure 2 degrees of freedom $\mathrm{H} \infty$ loop shaping controller. There is no information about the performance comparison between all of the synthesized simple structure Hळ controllers mentioned above with the high order traditional controller of $\mathrm{H} \infty$ synthesis.

This research contribution is to provide a structure-specified low-order H $\infty$ robust controller synthesis method and its performance comparison to a high order $\mathrm{H} \infty$ controller from a traditional synthesis. The proposed controller performance was also compared to a well-tuned PID controller and another structure specified $\mathrm{H} \infty$ controller from the MATLAB toolbox synthesis method. The advantage of a low-order with a simple-structure controller is its possibility to be programmed on a small embedded device [39].

\section{RESEARCH METHOD}

The proposed controller is a Structure Specified Low-Order Hœ Robust Controller. Due to its simplicity, the chosen structure for the proposed controller is a PID controller structure. The Hळ norm was optimized using the Differential Evolution optimization method. The steps to synthesis the controller are:

1. Define the plant transfer function

2. Define the uncertainties on the plant transfer function.

3. Plot the singular value of all the uncertainties.

4. Define the complementary sensitivity weight function $\left(W_{t}\right)$ that bounds all the uncertainties.

5. Define the sensitivity weight function $\left(W_{s}\right)$

6. Find the controller that satisfies the cost function $J_{\infty, a}$ and $J_{\infty, b}$

7. Check whether the controller satisfies the robust stability against perturbation and robust performance from the plot of the sensitivity and the complementary sensitivity of the system and the inverse of the above weights singular value.

\subsection{MOTOR MATHEMATIC MODEL}

The equivalent of the electrical circuit and mechanical diagram of a DC motor is shown in Fig. 1. The motor torque is proportional to the armature current.

$$
T=K i
$$

The back emf is proportional to the angular velocity of the rotor.

$$
e=K \dot{\theta}
$$

From Fig. 1, and by considering (1) and (2), the transfer function of the DC motor can be derived into:

$$
\begin{gathered}
J \ddot{\theta}+b \dot{\theta}=K i \\
L \frac{d i}{d t}+R i=V-K \dot{\theta}
\end{gathered}
$$




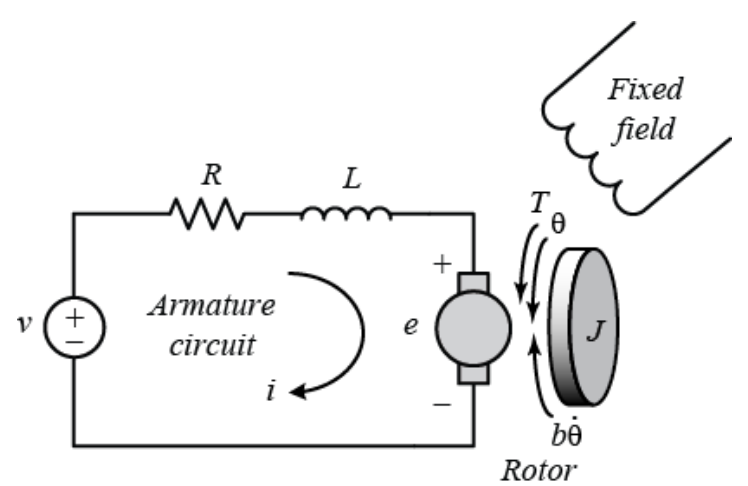

Fig. 1. The DC motor electrical and mechanical diagram

where $T$ is motor torque, $K$ is the torque constant, $i$ is motor current, $e$ is back EMF constant, $R$ is armature resistance, $L$ is armature inductance, $J$ is rotor inertia, $b$ is viscous friction constant, $\theta$ : rotor angular position, $\dot{\theta}$ is rotor angular velocity and $V$ is input voltage.

The DC motor transfer function with input voltage $V(s)$ and output angular position $\Theta(s)$ becomes:

$$
\frac{\Theta(s)}{V(s)}=\frac{K}{\left(s\left((J s+b)(L s+R)+K^{2}\right)\right)}
$$

After substitution of motor parameters from [40] into (5), the nominal transfer function DC motor position control is obtained as:

$$
\frac{\Theta(s)}{V(s)}=\frac{0.0274}{1.025 \times 10^{-11} s^{3}+1.491 \times 10^{-5} s^{2}+0.0007648 s}
$$

\subsection{CONTROLLER SYNTHESIS}

A robust controller is expected to perform well even in the presence of disturbance or when some unmodeled dynamics exist. However, the uncertainties should always be in some boundary value. This research uses load variation as the system uncertainty. The uncertainties of the load were varied $\pm 30 \%$ from the nominal value. The singular plot of the uncertainties and the upper bound complementary sensitivity weight is shown in Fig. 2.

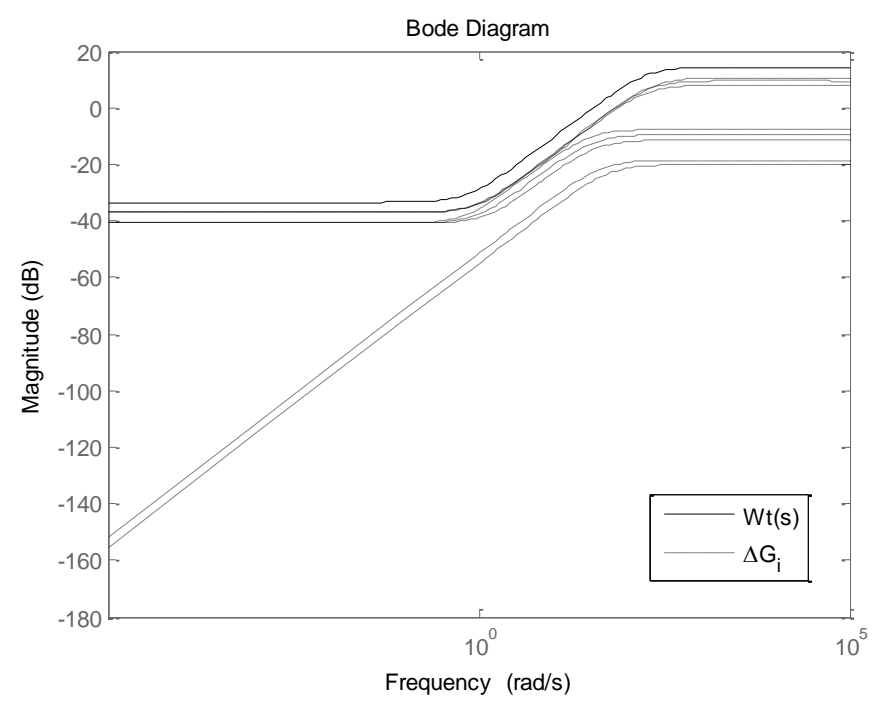

Fig. 2. The singular plot of DC motor uncertainties upper-bonded by $W_{t}(s)$

Robust stability performance against external disturbance is achieved when the following equation is satisfied [41]:

An Improved DC Motor Position Control Using Differential Evolution Based Structure Specified Hœ Robust Controller (Petrus Sutyasadi) 


$$
J_{\infty, a}=\left\|W_{s}(s) S(s)\right\|_{\infty}<1
$$

Robust stability against system perturbation satisfies the following equation:

$$
J_{\infty, b}=\left\|W_{t}(s) T(s)\right\|_{\infty}<1
$$

Hence, equations (7) and (8) become the objective function of the Differential Evolution Optimization. $S(s)$ and $T(s)$ are the sensitivity and complementary sensitivity functions, respectively. The uncertainties were upper bonded by complementary sensitivity weight $W_{t}(s)$.

$$
W_{t}(s)=\frac{5.246 s+3.805}{s+178.8}
$$

The sensitivity weight $W_{s}(s)$ was chosen following [41] to be:

$$
W_{s}(s)=\frac{0.5 s+1}{s+0.001}
$$

The chosen controller structure for the proposed DE-based Hळ Robust Controller is a PID structure with $K p$ is the Proportional constant, $K i$ is the Integral constant, and $K d$ is the Derivative constant.

$$
K=K p+\frac{K i}{s}+K d s
$$

By using the Differential Evolution optimization, the parameters of the controller are achieved. Setting parameters of the DE optimization are set as follows: number of population $=20$, differential weight $=0.8$, and crossover probability $=0.7$. Fig. 3 to Fig. 5 show the evolution of the PID structure parameters $K p, K i$, and $K d$ during the DE optimization. Finally, the $K p$ parameter achieved is 4.5976, the $K i$ parameter is 0.9996 , and the $K d$ parameter is 0.2334 . Hence, the result of the DE-based Hळ Robust Controller is:

$$
K=4.5976+\frac{0.9996}{s}+0.2334 s
$$

Even the controller is only in the form of a PID controller. It satisfies the robust stability and robust performance. Fig. 6 depicts a single plot of the sensitivity function, complementary sensitivity function, and the inverse of their weights. The inverse of the weights upper-bond the sensitivities function. It indicates that the proposed controller meets the stability criteria of robust controller performance.

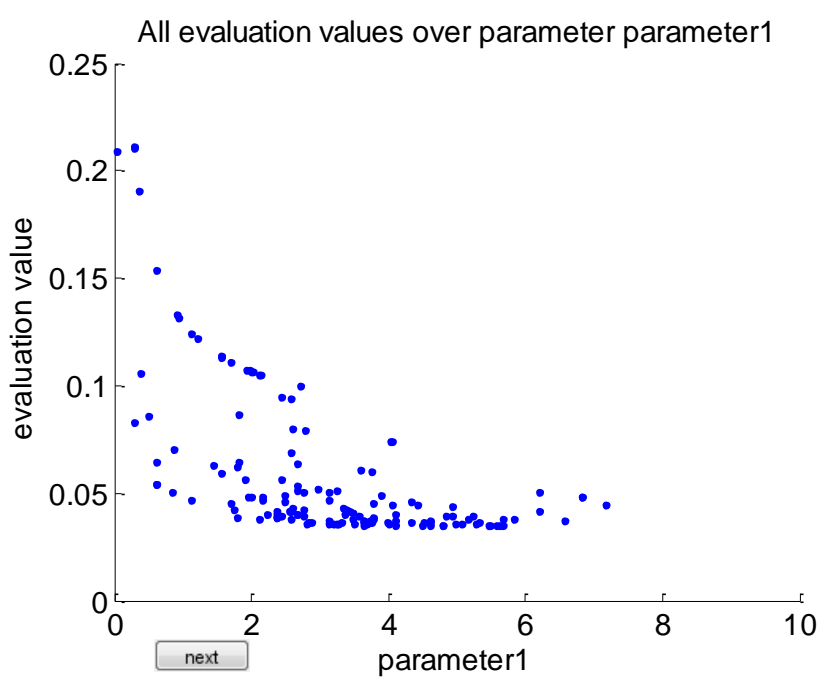

Fig. 3. The evolution of Parameter $K p$ finally converge to 4.5976 


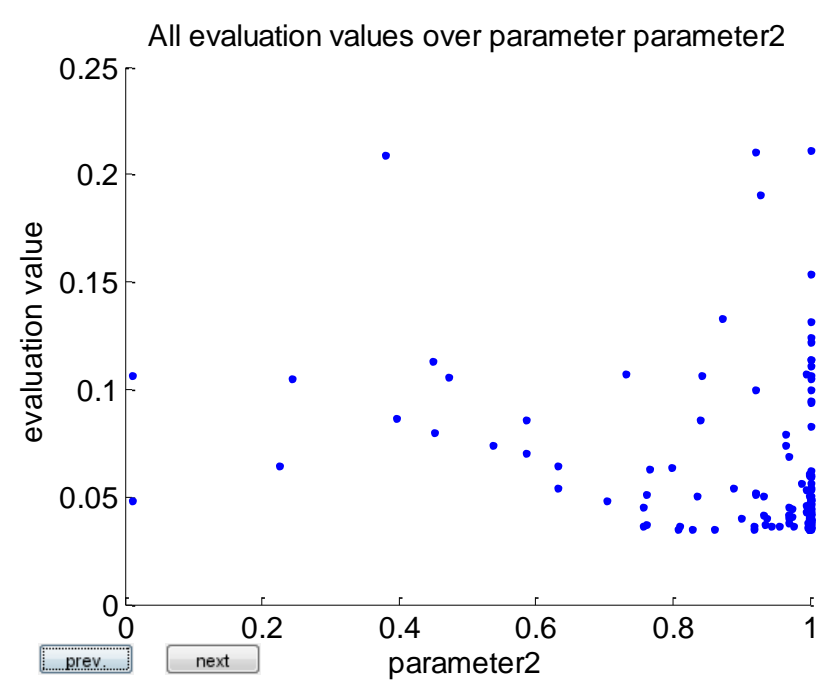

Fig. 4. The evolution of Parameter $K i$ finally converges to 0.9996

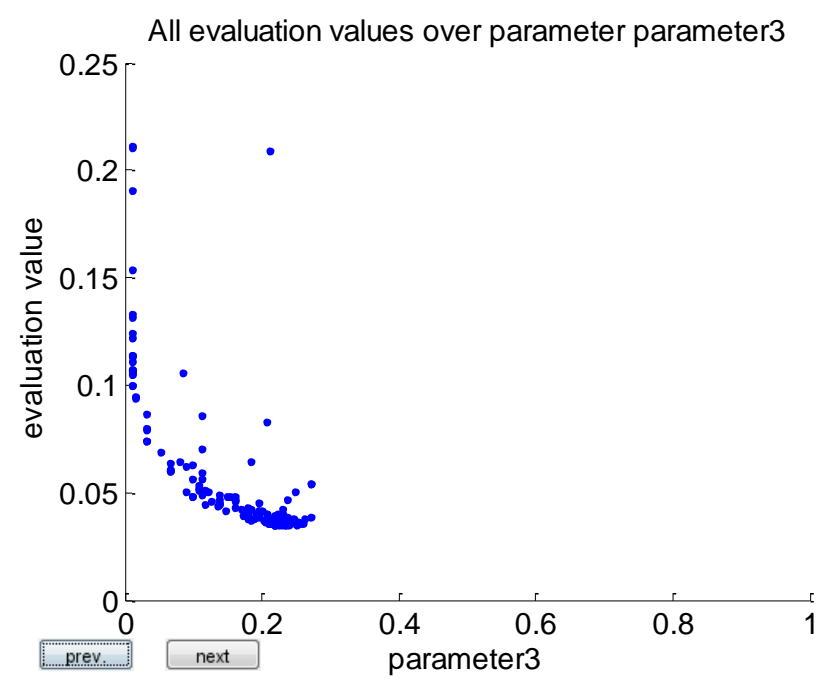

Fig. 5. The evolution of Parameter $K d$ finally converge to 0.2334

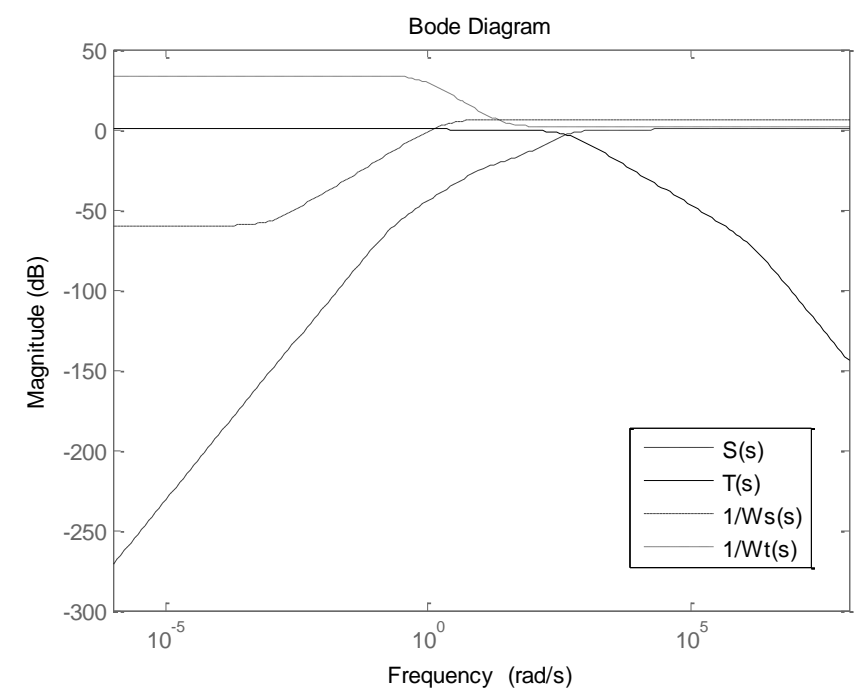

Fig. 6. The sensitivity, complementary sensitivity derived from DE based controller and their weights inverse singular plot 


\section{RESULTS AND DISCUSSION}

The performance of the DE-based structure specified $H_{\infty}$ controller under uncertainties is shown in Fig. 7. The uncertainties are mentioned in section 3 as $\pm 30 \%$ load variation from the nominal value. The proposed DE-based structure specified $H_{\infty}$ robust controller shows that under all variation or all uncertainties, the controller performs satisfactorily. The output responses do not vary too much. Even the dynamic model of the system varies due to the changing of the load.

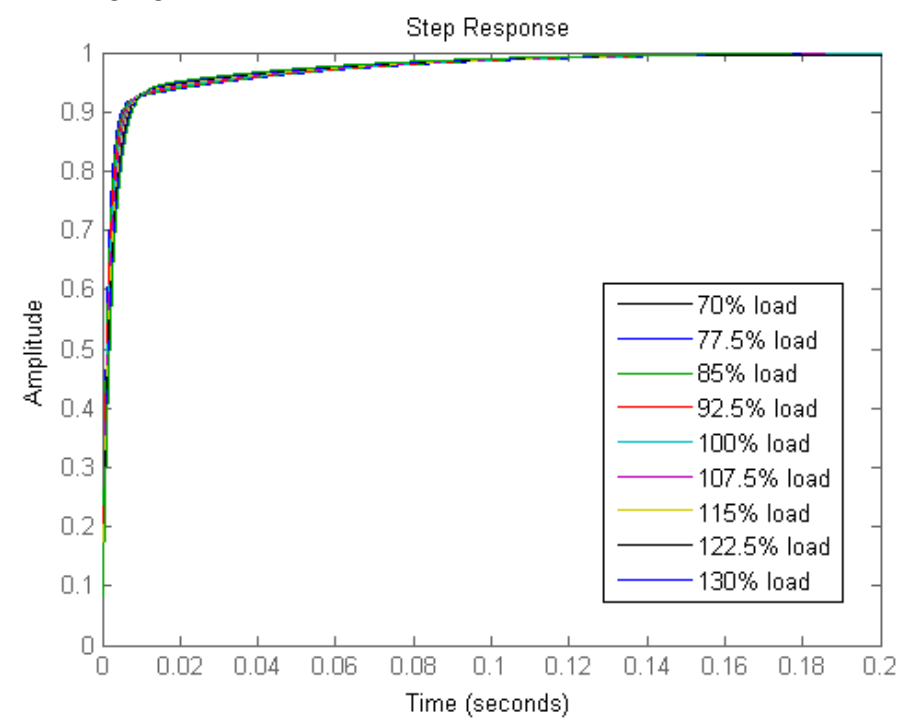

Fig. 7. The proposed DE based $H_{\infty}$ controller performance under uncertainties $( \pm 30 \%$ load variation)

The proposed controller was compared to a conventional PID controller. Even the controller has the same structure. The proposed controller has controller constants that were generated optimally based on the Hळ robust stability and robust performance cost function. From the point of view of a PID controller, it looks like a tuning method to find the controller constants that satisfy the robust stability and robust performance. It is common to tune a PID controller using trial and error mode for a particular system. However, it is almost impossible to find the combination of controller constants using the trial and error method that makes the system always stable under any bounded uncertainties. Especially when the uncertainties appear on more than one variable. So, in this experiment, the parameters of the DC motor were taken from [9]. Therefore, the best combination of the PID constants was also taken from [9]. Fig. 8 shows the performance of the conventional PID controller under uncertainties.

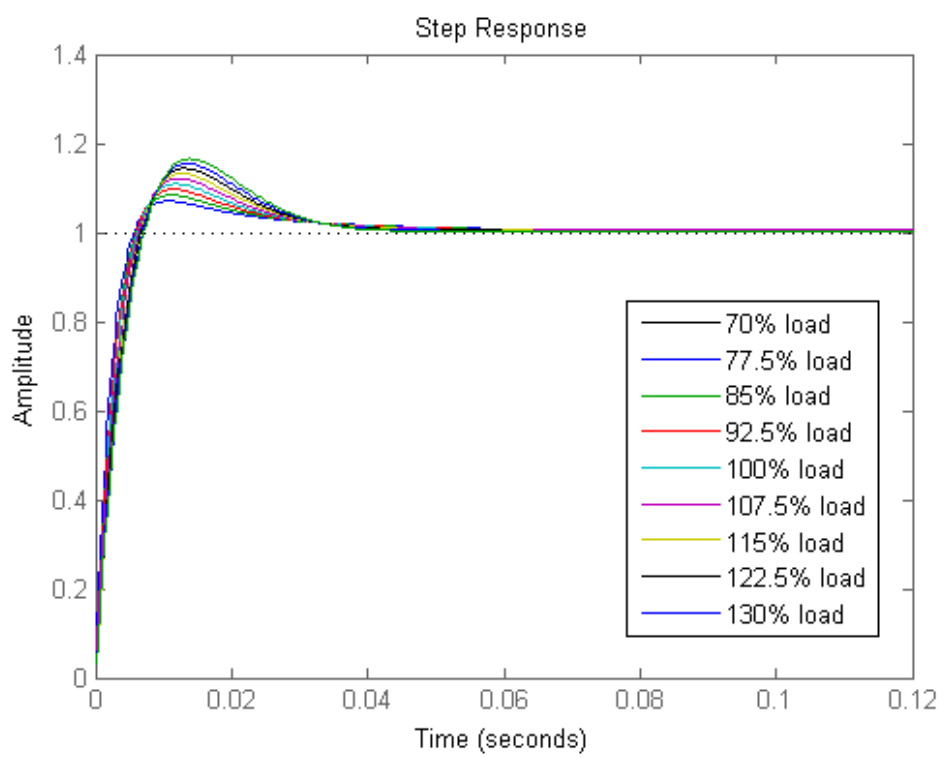

Fig. 8. The well-tuned conventional PID controller performance under uncertainties ( $\pm 30 \%$ load variation) 
The proposed controller outperforms the PID controller in the nominal transfer function or the transfer function without uncertainties. PID controllers, on the other hand, have large overshoots when there are uncertainties. Besides comparing to a conventional PID controller, the proposed controller was also compared to a high order $\mathrm{H}_{\infty}$ controller. A high-order $\mathrm{H}_{\infty}$ controller was designed to test the optimum efficiency of the proposed $\mathrm{H}_{\infty}$ controller. The high order $\mathrm{H}_{\infty}$ controller obtained by using Matlab's mixsyn command is:

$$
K=\frac{4.49 \times 10^{9} s^{4}+6.531 \times 10^{15} s^{3}+1.503 \times 10^{18} s^{2}+5.988 \times 10^{19} s-2.653 \times 10^{15}}{s^{5}+3.146 \times 10^{6} s^{4}+3.889 \times 10^{12} s^{3}+2.415 \times 10^{18} s^{2}+1.072 \times 10^{21} s+1.072 \times 10^{18}}
$$

The singular plot of the sensitivity function and its weights generated using the high order controller is plotted in Fig. 9. It shows that the high order controller also satisfies the robust stability against perturbation and robust performance.

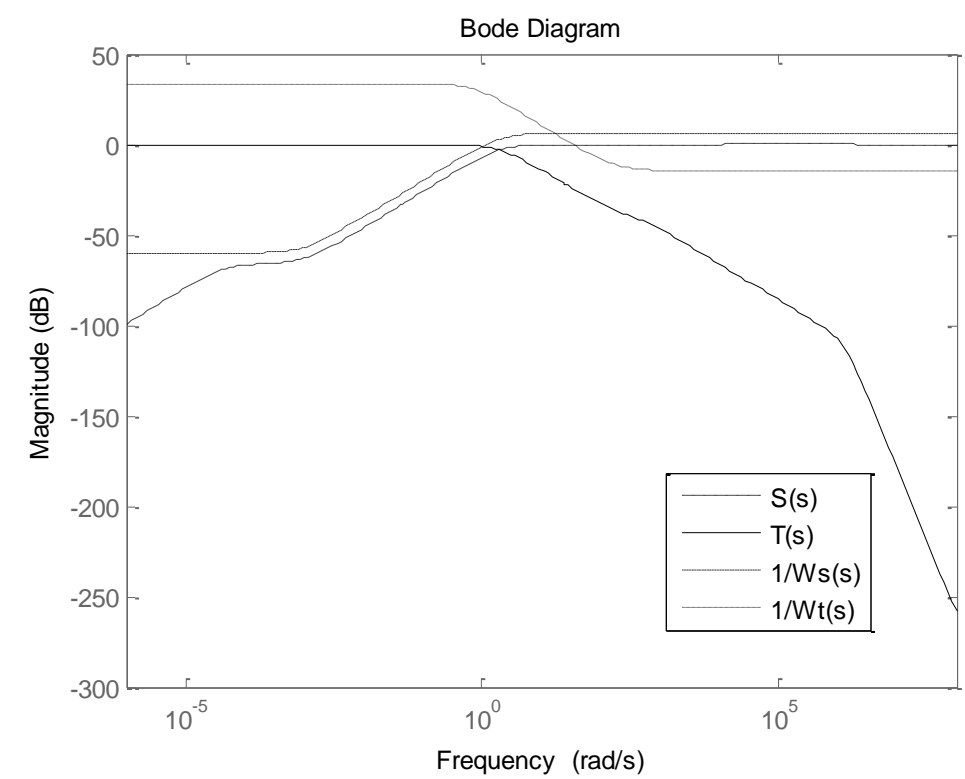

Fig. 9. The sensitivity, complementary sensitivity derived from the full order controller and their weights singular plot

The performances of the high-order controller under the same uncertainties as the previous test using the proposed controller are shown in Fig. 10. The high-order controller works very well. The system responses seem do not affected by the uncertainties. However, the rise time of all responses was too slow compared to the proposed controller and the conventional PID controller.

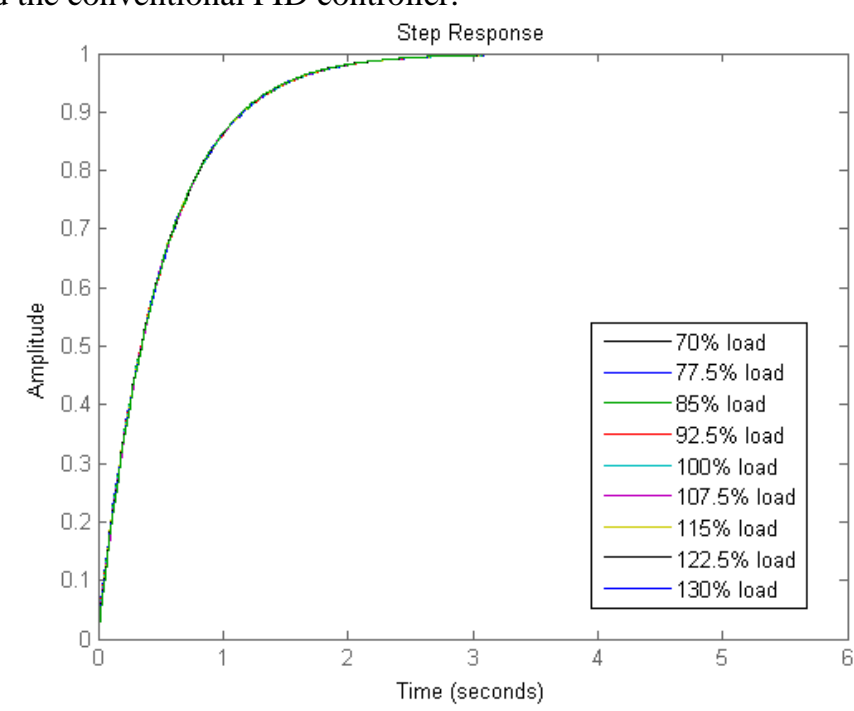

Fig. 10. The performance of full order $H_{\infty}$ controller under uncertainties ( $\pm 30 \%$ load variation) 
Matlab also provides tools to synthesize structure specified $H_{\infty}$ robust controller called ' $h i n f$ struct' command. Hinfstruct based structure specified controller was also developed to compare the proposed DE-based structure specified $H_{\infty}$ controller performance.

PID structure was also chosen for the hinfstruct based $H_{\infty}$ controller.

$$
K=K p+\frac{K i}{s}+K d \frac{s}{\tau s+1}
$$

The resulted controller using the hinfstruct command is:

$$
K=0.0558+\frac{5.58 \times 10^{-9}}{s}+4.31 \frac{s}{3.71 \times 10^{6} s+1}
$$

The singular plot of sensitivity function, complementary sensitivity function, and inverse of their weights using the new controller is plotted in Fig. 11. It shows that the Hinfstruct based structure specified controller also satisfies the robust performance and robust stability against perturbation.

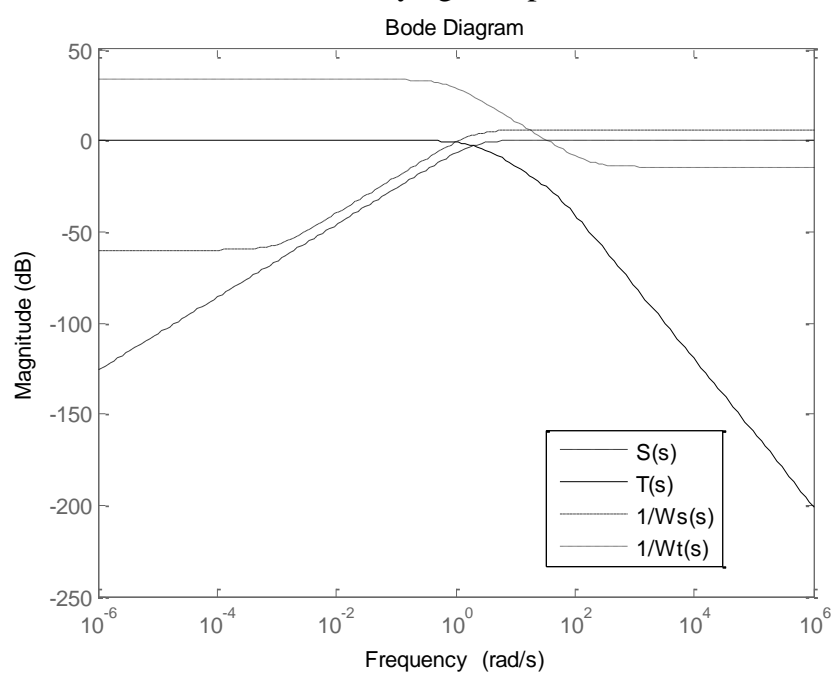

Fig. 11. The sensitivity, complementary sensitivity derived from hinfstruct based controller and their weights singular plot

The performance of the resulted hinfstruct based Ho controller is shown in Fig. 12. The graph shows that the performance of the hinfstruct based $\mathrm{H} \infty$ controller under uncertainties is also very good. All system responses can be controlled in the same manner even there was exist some variations in the dynamics model. But the speed response is also very low. The rise time drops significantly compared to the proposed controller.

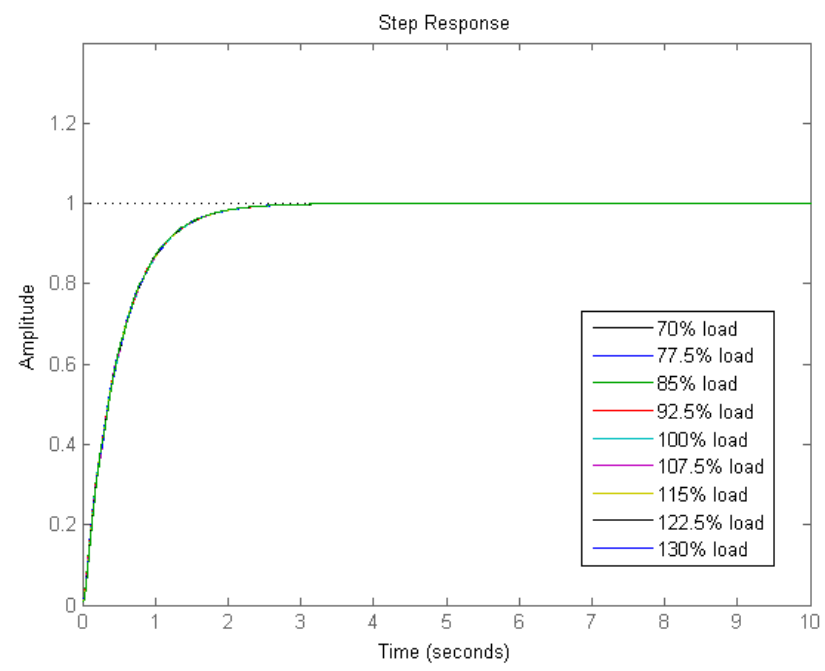

Fig. 12. The Hinfstruct based structure specified $H_{\infty}$ controller performance under uncertainties $( \pm 30 \%$ load variation)

An Improved DC Motor Position Control Using Differential Evolution Based Structure Specified Hœ Robust Controller (Petrus Sutyasadi) 


\section{CONCLUSION}

The DE-based structure specified Ho controller performed satisfactorily under uncertainties. It has less than 0.1 seconds of settling time in all conditions of uncertainties. There were no overshoot and no steady-state error. When unmodeled dynamics exist, only a few variations appear in the output responses. The well-tuned conventional PID also performed well. It has less than 0.1 seconds of settling time also. However, in some conditions, due to the uncertainties, some overshoots happened. The full order $H \infty$ controller and the hinfstruct based structure specified $H \infty$ gave almost the same performance. Both of them had a long settling time but no overshoot. However, both of them gave consistent performance even under uncertainties. It can be concluded that the proposed controller has flexibility in tailoring the controller during the controller synthesis. The robust performance and the robust stability were guaranteed, and the response characteristic can be adjusted by designing the weight according to the needs. Unlike the other two $H \infty 0$ controllers, which were synthesized using Matlab tools mixsyn and hinfstruct that also performed very well, but the response was too slow and could not be altered.

\section{REFERENCES}

[1] M. Iwasaki, K. Seki and Y. Maeda, "High- precision motion control techniques: A promising approach to improving motion performance," IEEE Ind. Electron. Mag., vol. 6, no. 1, pp. 32-40, 2012. https://doi.org/10.1109/MIE.2012.2182859

[2] A. Ma'arif, Iswanto, N. M. Raharja, P. A. Rosyady, A. R. Cahya Baswara and A. A. Nuryono, "Control of DC Motor Using Proportional Integral Derivative (PID): Arduino Hardware Implementation," in 2020 2nd International Conference on Industrial Electrical and Electronics (ICIEE), Lombok, Indonesia, 2020. https://doi.org/10.1109/ICIEE49813.2020.9277258

[3] Y. B. Koca, Y. Aslan and B. Gokce, "Speed Control Based PID Configuration of a DC Motor for An Unmanned Agricultural Vehicle," in 2021 8th International Conference on Electrical and Electronics Engineering (ICEEE), Antalya, Turkey, 2021. https://doi.org/10.1109/ICEEE52452.2021.9415908

[4] S. Balamurugan and A. Umarani, "Study of Discrete PID Controller for DC Motor Speed Control Using MATLAB," in 2020 International Conference on Computing and Information Technology (ICCIT-1441), Tabuk, Saudi Arabia, 2020. https://doi.org/10.1109/ICCIT-144147971.2020.9213780

[5] S. A. Hamoodi, I. I. Sheet and R. A. Mohammed, "A Comparison between PID controller and ANN controller for speed control of DC Motor," in 2nd International Conference on Electrical, Communication, Computer, Power and Control Engineering (ICECCPCE), Mosul, Iraq, 2019. https://doi.org/10.1109/ICECCPCE46549.2019.203777

[6] M. Mahmud, A. H. Motakabber, A. H. Zahirul Alam and A. N. Nordin, "Adaptive PID Controller Using for Speed Control of the BLDC Motor," in 2020 IEEE International Conference on Semiconductor Electronics (ICSE), Kuala Lumpur, Malaysia, 2020. https://doi.org/10.1109/ICSE49846.2020.9166883

[7] A. Mamadapur and G. U. Mahadev, "Speed Control of BLDC Motor Using Neural Network Controller and PID Controller," in 2019 2nd International Conference on Power and Embedded Drive Control (ICPEDC), Chennai, India, 2019. https://doi.org/10.1109/ICPEDC47771.2019.9036695

[8] B. Siciliano, L. Sciavicco, L. Villani and G. Oriolo, Robotics: Modelling, Planning and Control, Berlin, Germany: Springer Science \& Business Media, 2010. https://doi.org/10.1007/978-1-84628-642-1

[9] F. Vidussi, P. Boscariol, L. Scalera and A. Gasparetto, "Local and trajectory-based indexes for task-related energetic performance optimization of robotic manipulators," J. Mech. Robot, vol. 13, no. 2, 2021. https://doi.org/10.1115/1.4049972

[10] P. Boscariol, A. Gasparetto and V. Zanotto, "Model predictive control of a flexible links mechanism," J. Intell. Robot. Syst., vol. 2010, no. 58, p. 125-147, 2010. https://doi.org/10.1007/s10846-009-9347-5

[11] G. Trigatti, P. Boscariol, L. Scalera, D. Pillan and A. Gasparetto, "A look-ahead trajectory planning algorithm for spray painting robots with non-spherical wrists," Mechanisms and Machine Science, vol. 66, p. 235-242, 2019. https://doi.org/10.1007/978-3-030-00365-4_28

[12] R. Vidoni, A. Gasparetto and M. Giovagnoni, "A method for modelling three-dimensional flexible mechanisms based on an equivalent rigid-link system," J. Vib. Control, vol. 20, p. 483-500, 2014. https://doi.org/10.1177/1077546312463745

[13] L. Scalera, G. Carabin, R. Vidoni and T. Wongratanaphisan, "Energy efficiency in a 4-DOF parallel robot featuring compliant elements," Int. J. Mech. Control, vol. 20, p. 49-57, 2019. https://www.researchgate.net/profile/LorenzoScalera/publication/337901565

[14] X. Zhangbao, Y. Jianyong, M. Dawei and Y. Guichao, "'Robust control of DC motors based on disturbance estimation," in 34th Chinese Control Conference (CCC), 2015. https://doi.org/10.1109/ChiCC.2015.7260296

[15] F. Alyaqout S, Y. Alyaqout P and G. Ulsoy A, "“CCombined robust design and robust control of an electric DC motor," IEEE/ASME Trans. Mechatronics, vol. 16, no. 3, p. 574-582, 2011. https://doi.org/10.1109/TMECH.2010.2047652

[16] R. Errouissi, M. Ouhrouche, H. Chen W and M. Trzynadlowski A, "Robust nonlinear predictive controller for permanent-magnet synchronous motors with an optimized cost function," IEEE Trans. Ind. Electron., vol. 59, no. 7, p. 2849-2858, 2012. https://doi.org/10.1109/TIE.2011.2157276 
[17] A. Sabanovic, "Variable structure systems with sliding modes in motion control-A survey," IEEE Trans. Ind. Informat, vol. 7, no. 2, pp. 212-223, 2011. https://doi.org/10.1109/TII.2011.2123907

[18] P. Gábor, M. György and K. Bálint, "Implementation of a Robust Electric Brake Actuator Design Based on H-infinity Control Theory," Periodica Polytechnica Transportation Engineering, vol. 47, no. 3, pp. 178-185, 2019. https://doi.org/10.3311/PPtr.12104

[19] J. Doyle, K. Glover, P. Khargonekar and A. Francis, "State-space solutions to standard H2 and H1 control problems," IEEE Trans. Aut. Control, vol. 34, no. 8, p. 831-847, 1989. https://doi.org/10.1109/9.29425

[20] K. Zhou, C. Doyle J and K. Glover, Robust and Optimal Control, Prentice Hall, 1996.

[21] D. McFarlane and K. Glover, "A loop shaping design procedure using Ho synthesis," IEEE Trans. Aut. Control, vol. 37, no. 6, p. 759-769, 1992. https://doi.org/10.1109/9.256330

[22] A. T. Azar, F. E. Serrano and N. A. Kamal, "Robust Ho Loop Shaping Controller Synthesis for SISO Systems by Complex Modular," Math. Comput. Appl., vol. 21, p. 26, 2021. https://doi.org/10.3390/mca26010021

[23] B. Meghni, D. Dib, A. T. Azar, S. Ghoudelbourk and A. Saadoun, "Robust Adaptive Supervisory Fractional Order Controller for," in Fractional Order Control and Synchronization of Chaotic, Cham, Switzerland, Springer International Publishing, 2017, p. 165-202. https://doi.org/10.1007/978-3-319-50249-6_6

[24] A. Kojima and Y. Ichikawa, "H-infinity loop-shaping procedure for multiple input delay systems," in the 46th IEEE Conference on Decision and Control, New Orleans, LA, USA, 2007. https://doi.org/10.1109/CDC.2007.4434362

[25] S. L. Zhou, P. Han, D. F. Wang and Y. Y. Liu, "A kind of multivariable PID design method for chaos system - using $\mathrm{H} / \mathrm{sub} / \mathrm{spl}$ infin// loop shaping design procedure," in The 2004 International Conference on Machine Learning and Cybernetics, Shanghai, China, 2004. https://doi.org/10.1109/ICMLC.2004.1382294

[26] C. Stein and J. C. Doyle, "Beyond singular values and loop shapes," J. Guidance and Control, vol. 14, pp. 5-16, 1991. https://doi.org/10.2514/3.20598

[27] R. L. Pereira and K. H. Kienitz, "H-infinity Loop Shaping Control of Input Saturated Systems with Norm Bounded Parametric Uncertainty," J. Control. Sci. Eng., vol. 2015, 2015. https://doi.org/10.1155/2015/383297

[28] N. Ouddah, M. Boukhnifer, A. Chaibet and E. Monmasson, "Fixed structure H $\infty$ loop shaping control of switched reluctance motor for electrical vehicle," Mathematics and Computers in Simulation, vol. 130(C), pp. 124-141, 2016. https://doi.org/10.1016/j.matcom.2015.09.014

[29] S. Iqbal, A. I. Bhatti, M. Akhtar and S. Ullah, "Design and robustness evaluation of an H-infinity loop shaping controller for a 2DOF stabilized platform," in The 2007 European Control Conference (ECC), Kos, Greece, 2007. https://doi.org/10.23919/ECC.2007.7068609

[30] F. Boeren, R. van Herpen, T. Oomen, M. van de Wal and O. Bosgra, "Enhancing performance through multivariable weighting function design in H-infinity loop-shaping with application to a motion system," in The 2013 American Control Conference, Washington, DC, USA, 2013. https://doi.org/10.1109/ACC.2013.6580784

[31] M. Osinuga, S. Patra and A. Lanzon, "Weight optimization for maximizing robust performance in H-infinity loopshaping design," in International Federation of Automatic Control (IFAC) Conference, 2011. https://doi.org/10.3182/20110828-6-IT-1002.00153

[32] S. Formentin, A. Karimi and S. M. Savaresi, "Direct data-driven H2-H-infinity loop-shaping," in International Federation of Automatic Control (IFAC) proc, 2011. https://doi.org/10.3182/20110828-6-IT-1002.01570

[33] S. Amini, H. Golpira and H. Bevrani, "Robust $\mathrm{H} 2$ and $\mathrm{H} \infty$ controller design for DC position motor control under uncertainties," in 6th International Conference on Control, Instrumentation and Automation (ICCIA), 2019. https://doi.org/10.1109/ICCIA49288.2019.9030972

[34] U. Chaiya and S. Kaitwanidvilai, "“Fixed-Structure Robust DC Motor Speed Control," in International MultiConference of Engineers and Computer Scientists, Hong Kong, 2009. https://citeseerx.ist.psu.edu/viewdoc/download?doi=10.1.1.148.9645\&rep=rep1\&type=pdf

[35] P. Olranthichachat and S. Kaitwanidvilai, "Structure Specified Robust Ho Loop Shaping Control of a MIMO ElectroHydraulic Servo System using Particle Swarm Optimization," in International Multiconference of Engineers and $\begin{array}{llll}\text { Computer Scientist, } & \text { Hong } & \text { Kong, }\end{array}$ http://citeseerx.ist.psu.edu/viewdoc/download?doi=10.1.1.420.7561\&rep=rep1\&type=pdf

[36] S. Kaitwanidvilai and M. Parnichkun, "Genetic Algorithm based Fixed-Structure Robust H infinity Loop Shaping Control of a Pneumatic Servo System," International Journal of Robotics and Mechatronics, vol. 16, no. 4, 2004. https://www.researchgate.net/profile/M-Parnichkun/publication/4144714

[37] P. Sutyasadi and M. Parnichkun, "“Gait Tracking Control of Quadruped Robot Using Differential Evolution Based Structure Specified Mixed Sensitivity Robust Control," Journal of Control Science and Engineering, vol. 2016, 2016. https://doi.org/10.1155/2016/8760215

[38] N. Phurahong, S. Kaitwanidvilai and A. Ngaopitakkul, "Fixed Structure Robust 2DOF H-infinity Loop Shaping Control for ACMC Buck Converter using Genetic Algorithm," in The International Multiconference of Engineers and Computer Scientist 2012, Hong Kong, China, 2012. https://doi.org/10.1109/ECTICon.2012.6254367

[39] P. Sutyasadi and B. Wicaksono M, "'Joint control of a robotic arm using particle swarm optimization based $\mathrm{H} 2 / \mathrm{H} \infty$ robust control on arduino," Telkomnika, vol. 18, no. 2, pp. 1021-1029, 2021. https://doi.org/10.12928/telkomnika.v18i2.14749 
[40] B. Messner and D. Tilbury, "DC Motor Position: PID Controller Design," 1997. [Online]. Available: http://ctms.engin.umich.edu/CTMS/index.php?example=MotorPosition\&section=ControlPID

[41] S. Skogestad and I. Postlethwaite, Multivariable Feedback Control, John Wiley \& Sons, 2001.

\section{BIOGRAPHY OF AUTHORS}

Petrus Sutyasadi earned his master degree in mechatronics in 2008 and doctoral degree in mechatronics in 2016 from the Asian Institute of Technology, Thailand. Currently he is a lecturer at Mechatronics Department of Sanata Dharma University, Yogyakarta, Indonesia. His research interest includes robust control, robotic, and frugal innovation in mechatronic engineering. 